\title{
Two species previously placed in Euconnus s. str. belong in the endemic Madagascan subgenus Glabriconnus (Coleoptera: Staphylinidae: Scydmaeninae)
}

\author{
Paweł JAŁOSZYŃSKI \\ Museum of Natural History, University of Wrocław, Sienkiewicza 21, 50-335 Wrocław, Poland; e-mail: scydmaenus@yahoo.com
}

\author{
Accepted: \\ $22^{\text {nd }}$ November 2018 \\ Published online: \\ $26^{\text {th }}$ November 2018
}

\begin{abstract}
The Madagascan species Euconnus andringitrae Franz, 1986 and E. berentyensis Franz, 1986 are redescribed and transferred from Euconnus s. str. to the subgenus Glabriconnus Jałoszyński, 2016. They share with E. (Glabriconnus) aterrimus Franz, 1986 the evenly convex frons and vertex, and lack of a pair of diffuse longitudinal carinae (present in all remaining species of Glabriconnus), and with E. (Glabriconnus) andranomenaus Jałoszyński, 2016 the presence of two distinct hypomeral grooves (one variously distinct groove in remaining Glabriconnus species). The unique character for Euconnus andringitrae and E. berentyensis is the transverse antebasal groove connecting a pair of lateral pits, which was not previously known in any other Glabriconnus. Consequently, the diagnosis of Glabriconnus is here emended to include a considerable variability in pronotal structures. The distribution of Glabriconnus in Madagascar is summarized.
\end{abstract}

Key words. Coleoptera, Scydmaeninae, Glandulariini, Euconnus, taxonomy, Madagascar

Zoobank: http://zoobank.org/urn:lsid:zoobank.org:pub:3D2D475A-4E53-4248-9808-0D3BDF8DE083

(C) 2018 The Authors. This work is licensed under the Creative Commons Attribution-NonCommercial-NoDerivs 3.0 Licence.

\section{Introduction}

Glabriconnus Jałoszyński, 2016, a subgenus of Euconnus Thomson, 1859, was recently established to accommodate four species, all known to occur in Madagascar: E. aterrimus Franz, 1986, E. banari Jałoszyński, 2016, E. andranomenaus Jałoszyński, 2016 and E. februarius Jałoszyński, 2016 (JAŁOSZYŃSKI 2016). Adults of Glabriconnus are similar to those of Euconnus s. str., Tetramelus Motschulsky, 1870 and Paratetramelus Franz, 1963, but can be easily distinguished by the unique hypomeral grooves running along each side of the pronotum, and by a conspicuous setal pattern composed of relatively short but dense and thick bristles on the genae, postgenae, anterior pronotal margin, and sides of pronotum, whereas the frons, vertex, pronotal disc and elytra are nearly glabrous, with only very sparse, thin, recumbent and barely noticeable setae. Also the body shape, the shape of the head, the antennal structure, and ventral characters of the head and thorax are very similar in all species of Glabriconnus. These shared characters strongly support the monophyly of this small but distinct group within Euconnus. Illustrations of morphological structures, and a detailed diagnosis and species treatment can be found in JAŁOSZYŃSKI (2016).

A survey of the Franz Collection, containing the majority of Euconnus species described by this prolific author in his large Madagascan monograph (FrANz 1986) was carried out before describing Glabriconnus, but the way some specimens had been originally mounted (e.g., largely covered with glue or soil particles) prevented me from detecting all species previously placed in other subgenera; note some of them show the unique hypomeral grooves and other features diagnostic for Glabriconnus. A subsequent repeated study revealed two more species among Euconnus s. str. that possibly belong to Glabriconnus. Remounting and cleaning the type specimens confirmed these suspicions. These species are redescribed below, and as they show some interesting characters not known in any previously treated species of Glabriconnus, the diagnosis of this endemic Madagascan taxon is also emended. 


\section{Materials and methods}

Dry-mounted specimens were relaxed in warm water, briefly cleaned in an ultrasonic cleaner (in water containing a small addition of a detergent) and dissected. Aedeagi of the holotypes, originally mounted in euparal, were remounted in Canada balsam. Habitus images were taken using a Nikon Coolpix 4500 digital camera mounted on a Nikon Eclipse 1500 stereoscopic microscope. Structures in transparent mounts were photographed using a Nikon D7500 camera mounted on a Nikon Eclipse $\mathrm{Ni}$ compound microscope. Image stacks were processed using COMBINE ZP (HAdley 2010) and Helicon Focus v. 6.8.0 (HeliconSoft Ltd.).

Morphological terms follow JAŁOSZYŃSKI (2016). The measurements and abbreviations applied here are as follows:

AeL length of aedeagus (from base to apex of median lobe);

AnL length of antennae, measured in dorsal view;

BL body length, a sum of lengths of head, pronotum and elytra measured separately;

EI elytral index, length of elytra divided by their combined width;

EL length of elytra measured along suture, from base to apex;

EW maximum width of elytra, combined;

$\mathrm{HL}$ length of anterior part of head capsule measured from anterior margin of clypeus to the posterior margin of vertex;

HW width of head, including eyes;

PL length of pronotum measured along midline;

PW width of pronotum.
The distribution map (Fig. 13) is based on an image obtained from the Demis World Map Server open source (http://webmap.iwmi.org/DataSrc.htm; currently unavailable).

All studied specimens are deposited in the Naturhistorisches Museum Wien, Vienna, Austria (NHMW). The label data are quoted verbatim, with a slash (/) used to separate lines of text; comments on the appearance of the labels (e.g., the color) are given in square brackets.

\section{Taxonomy \\ Emended diagnosis of Glabriconnus Jałoszyński, 2016}

Euconnus with unique lateral pronotal hypomeral grooves (faint in E. aterrimus); antennae gradually thickened or with barely marked tetramerous club; head 'anthiciform' with bristles on genae and postgenae, but not on tempora; pronotum broadest in front of middle or near middle, nearly glabrous dorsally and with dense bristles along anterior margin and below lateral hypomeral groove; base of pronotum with one pair of distinct lateral pits (in $E$. andringitrae and $E$. berentyensis connected by transverse groove), lacking sublateral carinae or with barely discernible, vestigial carinae; prosternum about as long as $1 / 3$ of prothorax; adcoxal margin of each hypomeron curved; mesonotum largely membranous, only with small subtri-
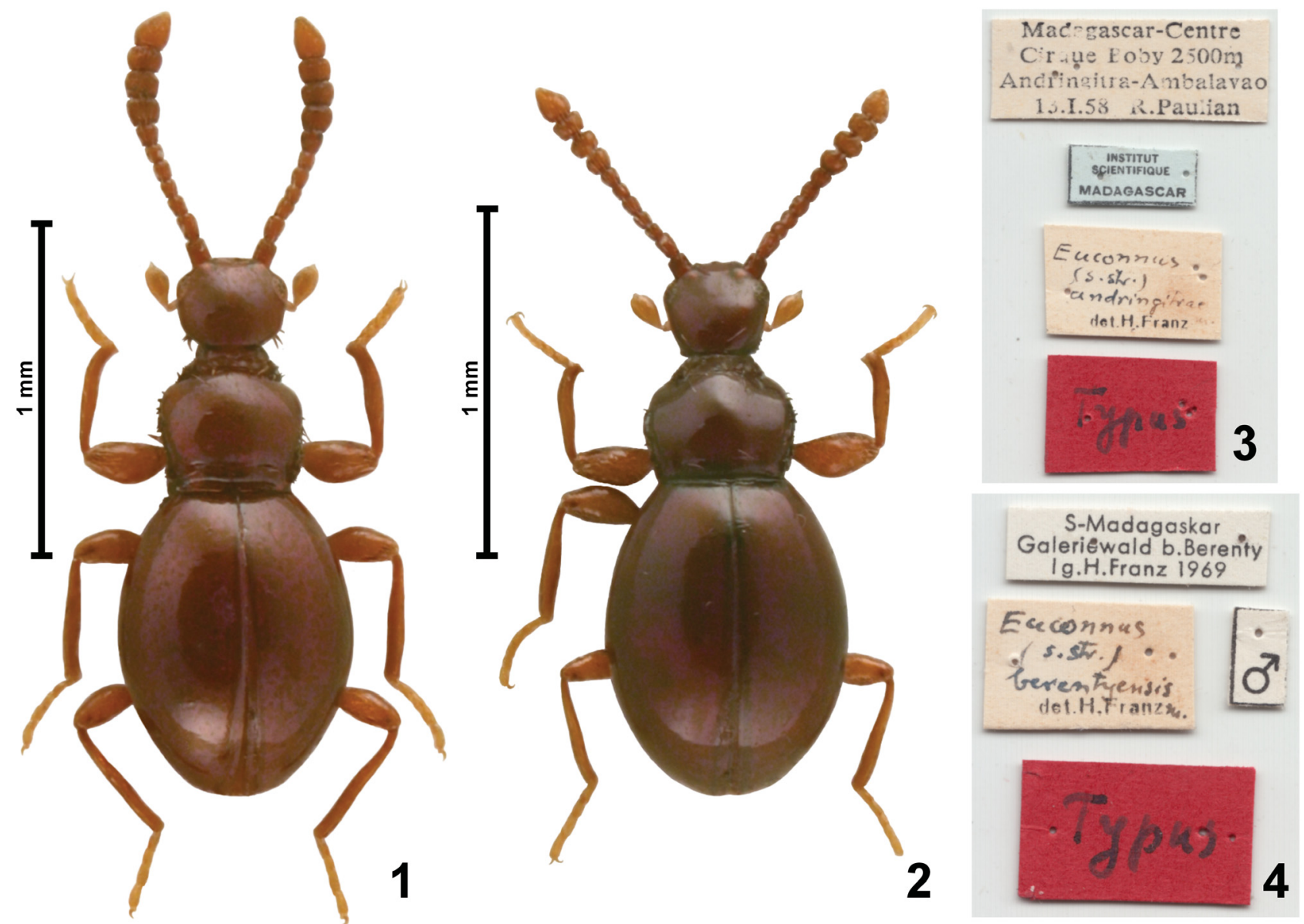

Figs 1-4. Dorsal habitus of male holotypes (1-2) and their original sets of labels (3-4). 1, 3-Euconnus andringitrae Franz, 1986; 2, 4-E. berentyensis Franz, 1986. 
angular mesoscutellum sclerotized, scutellum not visible between elytral bases; metanotum vestigial; hind wings, humeral calli, humeral impressions and subhumeral lines absent; elytra nearly glabrous.

\section{Euconnus (Glabriconnus) andringitrae Franz, 1968}

(Figs 1, 3, 5-8, 13)

Euconnus (s. str.) andringitrae Franz, 1986: 225, Fig. 200.

Type material. Holotyp: MADAGASCAR: (Fig. 1), four labels (Fig. 3): "Madagascar-Centre / Cirque Boby $2500 \mathrm{~m} /$ Andringitra-Ambalavao / 13.I.58 R.Paulian" [creamy white, printed], "INSTITUT / SCIENTIFIQUE / MADAGASCAR" [bluish, printed], "Euconnus / (s. str.) / andringitrae m. / det.H.Franz" [creamy white, handwritten and printed], "Typus" [red, handwritten] (NHMW).

Revised diagnosis. Small species, BL about $1.5 \mathrm{~mm}$; frons lacking longitudinal carinae; pronotum with two deep and distinct hypomeral carinae at each side; small lateral antebasal pronotal pits connected by deep transverse groove; aedeagus with pair of suboval lateral lobes in subapical region and apical portion of median lobe not constricted.
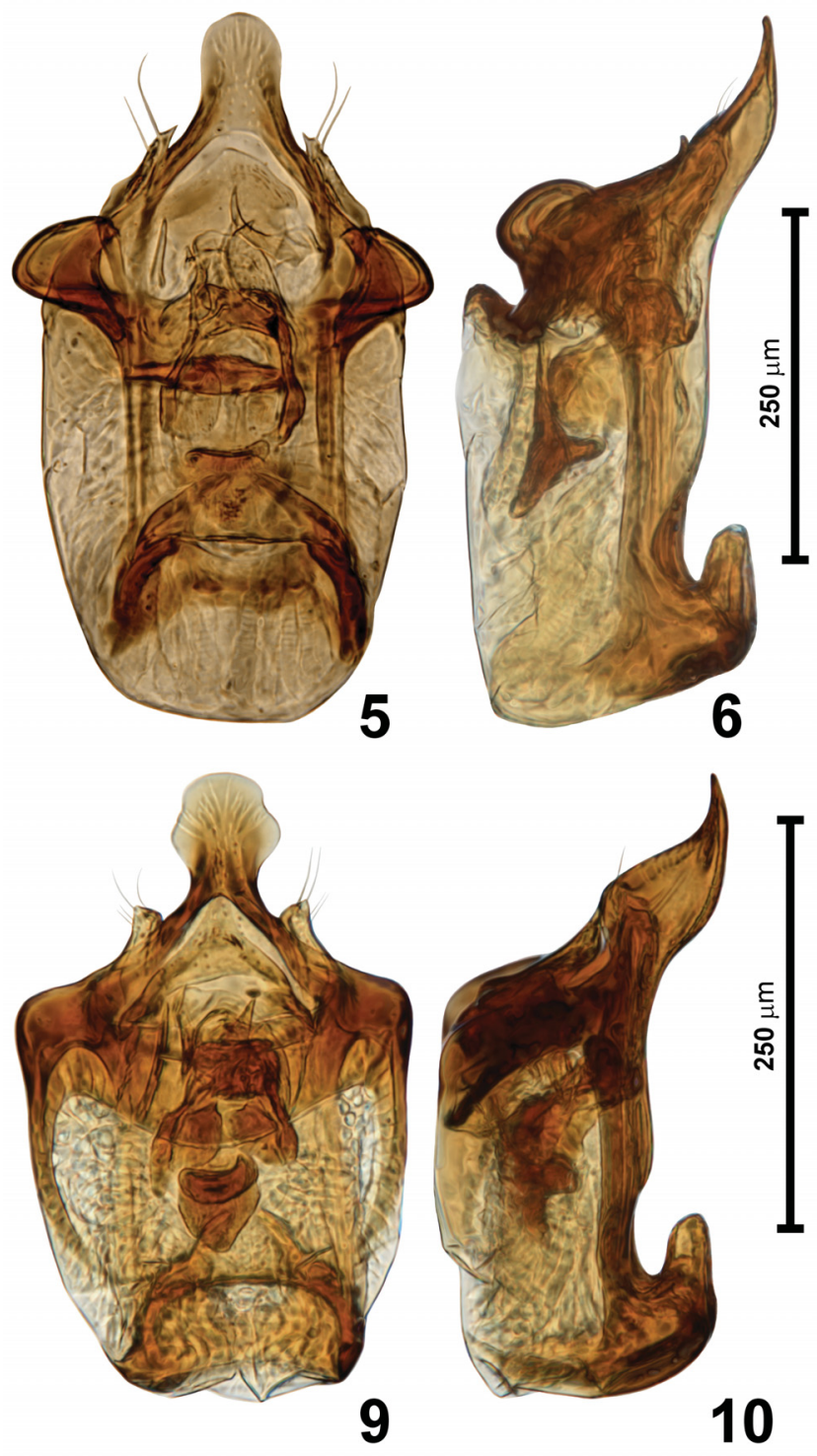

Redescription. Male. Body (Fig. 1) strongly convex, elongate with deep constrictions between head and pronotum and between pronotum and elytra, appendages long; BL $1.55 \mathrm{~mm}$; cuticle glossy, not opalescent, dark reddish-brown, only tarsi and palps lighter; setae yellowish, bristles nearly as dark as cuticle.

Head in dorsal view rounded, broadest at eyes, HL 0.30 mm, HW $0.33 \mathrm{~mm}$; vertex and frons confluent, lacking longitudinal carinae and weakly but distinctly convex; supraantennal tubercles weakly elevated; tempora about 2.5 times as long as eyes in dorsal view; eyes moderately large and moderately convex, coarsely faceted. Punctures on vertex and frons very fine and sparse, inconspicuous; setae on vertex and frons indiscernible; genae and postgeneae, but not tempora, with short and sparse thick bristles. Antennae moderately long, AnL $0.80 \mathrm{~mm}$; antennomeres I-VII each strongly elongate, VIII-X each strongly transverse, XI slightly broader than $\mathrm{X}$, slightly shorter than IX-X together, about 1.5 times as long as broad, with subconical and indistinctly pointed apex.

Pronotum in dorsal view subtrapezoidal, broadest at anterior fourth, PL $0.38 \mathrm{~mm}, \mathrm{PW} 0.45 \mathrm{~mm}$; anterior and
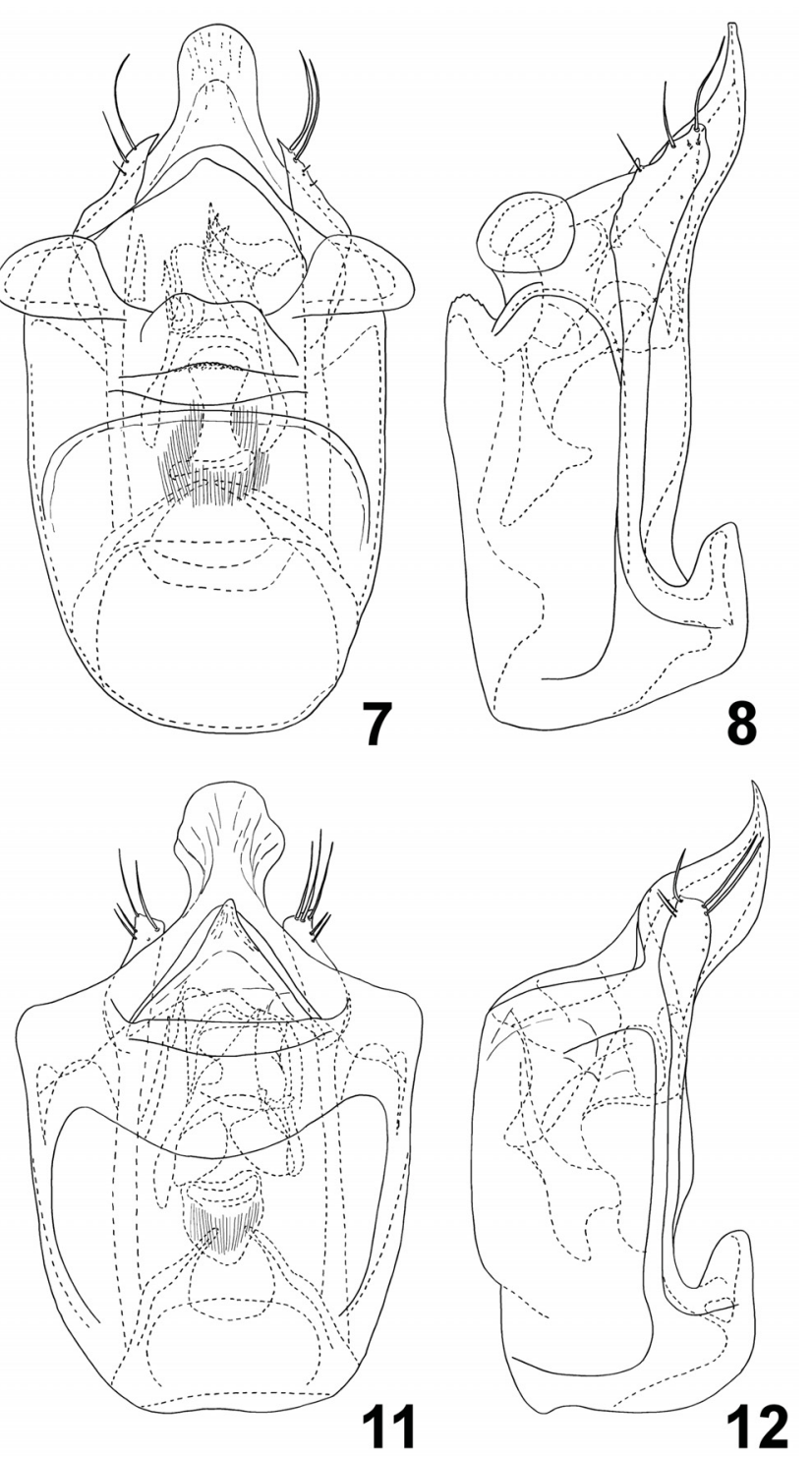

Figs 5-12. Aedeagus in ventral (5, 7, 9, 11) and lateral $(6,8,10,12)$ views. 5-8-Euconnus andringitrae Franz, 1986; 9-12-E. berentyensis Franz, 1986. 
posterior margins weakly arcuate; lateral margins strongly rounded in anterior third and nearly straight in posterior $2 / 3$, indistinctly sinuate just in front of posterior pronotal corners; base with one pair of small and shallow lateral pits connected by deep transverse groove; sublateral carinae present but diffuse; each side of pronotum with two parallel and deep hypomeral grooves distinct on entire length. Punctures on pronotal disc not visible at magnifications up to $80 \times$; vestiture composed of short and dense bristles distributed along anterior pronotal margin, between and below hypomeral grooves.

Elytra egg-shaped, broadest distinctly behind middle, EL $0.88 \mathrm{~mm}$, EW $0.70 \mathrm{~mm}$, EI 1.25; elytral base as broad as pronotal base, lacking impressions and humeral calli. Punctures on elytral disc as fine as those on pronotum; setae sparse and short, nearly recumbent, barely noticeable. Hind wings absent.

Legs moderately long and slender; protibiae rapidly bent mesad at apices and each with one small apical denticle.

Aedeagus (Figs 5-8) relatively stout and large in relation to body, AeL $0.50 \mathrm{~mm}$, median lobe in ventral view broadest in subapical region where it forms pair of rounded lateral lobes, apex subtriangular, not constricted and with almost evenly rounded distal margin; endophallic structures asymmetrical and complicated; parameres with broadened apices, each with two to three long apical and subapical setae and one to two short subapical setae.

Female. Unknown.

Distribution. Southern Madagascar (Fig. 13).

\section{Euconnus (Glabriconnus) berentyensis Franz, 1986} (Figs 2, 4, 9-12, 13)

Euconnus (s. str.) berentyensis Franz, 1986: 223, fig. 199.

Type material. Holotype: MADAGASCAR: $\delta$ (Fig. 2), four labels (Fig. 4): "S-Madagaskar / Galeriewald b. Berenty / lg.H.Franz 1969" with "Mg 42 " on the reverse side [white, printed; reverse handwritten], " $\$$ " [white, printed], "Euconnus / (s. str.) / berentyensis m. / det.H.Franz" [creamy white, handwritten and printed], "Typus" [red, handwritten] (NHMW). PARATypes ( 2 exx.; but see remarks): $2+q$, same data as for holotype except for yellow "Paratypus" labels (NHMW).

Revised diagnosis. Small species, BL about $1.5 \mathrm{~mm}$; frons lacking longitudinal carinae; pronotum with two deep and distinct hypomeral carinae at each side; small lateral antebasal pronotal pits connected by faint transverse groove; aedeagus lacking suboval lateral lobes in subapical region, and apical portion of median lobe deeply constricted.

Redescription. Male. Body (Fig. 2) strongly convex, elongate with deep constrictions between head and pronotum and between pronotum and elytra, appendages long; BL $1.55 \mathrm{~mm}$; glossy and slightly opalescent, dark brown, only tarsi and palps lighter; setae yellowish, bristles nearly as dark as cuticle.

Head in dorsal view slightly rhomboidal, broadest at eyes, HL $0.30 \mathrm{~mm}$, HW $0.30 \mathrm{~mm}$; vertex and frons confluent, lacking longitudinal carinae, distinctly flattened; supraantennal tubercles weakly elevated; tempora about 2.5 times as long as eyes in dorsal view; eyes moderately large and moderately convex, coarsely faceted. Punctures on vertex and frons markedly fine and sparse, inconspicuous; setae barely discernible, spare, thin and recumbent; genae and postgenae, but not tempora, with very short, dense thick bristles. Antennae relatively short, AnL 0.70 $\mathrm{mm}$; antennomeres I-VII each strongly elongate, VIII-X each strongly transverse, XI slightly broader than X, distinctly shorter than IX-X together, about 1.3 times as long as broad, with subconical and indistinctly pointed apex.

Pronotum in dorsal view subtrapezoidal, broadest at anterior fourth, PL $0.38 \mathrm{~mm}$, PW $0.43 \mathrm{~mm}$; sides in anterior fourth slightly impressed; anterior and posterior margins weakly arcuate; lateral margins strongly rounded in anterior third and weakly rounded in posterior $2 / 3$, not sinuate in front of posterior corners; base with one pair of small and shallow lateral pits connected by a shallow transverse groove; sublateral carinae present but diffuse; each side of pronotum with two parallel and very deep hypomeral grooves distinct on entire length, narrow area between them forming a rounded but strongly elevated carina. Punctures on pronotal disc not visible at magnifications up to $80 \times$; vestiture composed of very sparse thin setae, which are recumbent and barely noticeable, and of short and dense bristles distributed along anterior pronotal margin, between and below hypomeral grooves.

Elytra egg-shaped, broadest distinctly behind middle, EL $0.88 \mathrm{~mm}$, EW $0.70 \mathrm{~mm}$, EI 1.25; elytral base as broad as pronotal base, lacking impressions and humeral calli. Punctures on elytral disc as fine as those on pronotum; setae very sparse and short, nearly recumbent, barely noticeable. Hind wings absent.

Legs moderately long and slender; protibiae rapidly bent mesad at apices and each with a small apical denticle.

Aedeagus (Figs 9-10) stout and large in relation to body, AeL $0.38 \mathrm{~mm}$, median lobe in ventral view broadest in subapical region where it forms pair of rounded angles, apex strongly constricted, with sinuate sides and rounded distal margin; endophallic structures asymmetrical and complicated; parameres with broadened apices, each with two to three long apical and subapical setae and two short subapical setae.

Female. Unknown (see remarks below).

Distribution. Southernmost Madagascar (Fig. 13).

Remarks. The type series of this species is composed of a male holotype and two female paratypes collected in the same locality. However, the females, although undoubtedly belong to Glabriconnus, differ from the male in the shape of the pronotum, proportions of the body parts, and even in the shape of the elytra, which in the male are broadest behind middle, and in the females broadest at or even slightly in front of the middle. I regard Franz's identification of females as doubtful and do not include measurements and characters of these two specimens in the redescription.

\section{Discussion}

Euconnus andringitrae and E. berentyensis have the smallest adults among known species of Glabriconnus - the males measure merely $1.55 \mathrm{~mm}$. Euconnus banari and $E$. aterrimus exceed $2 \mathrm{~mm}$ in length (although only a female of the latter species is known; males may be slightly smaller), and E. andranomenaus and E. februarius measure 


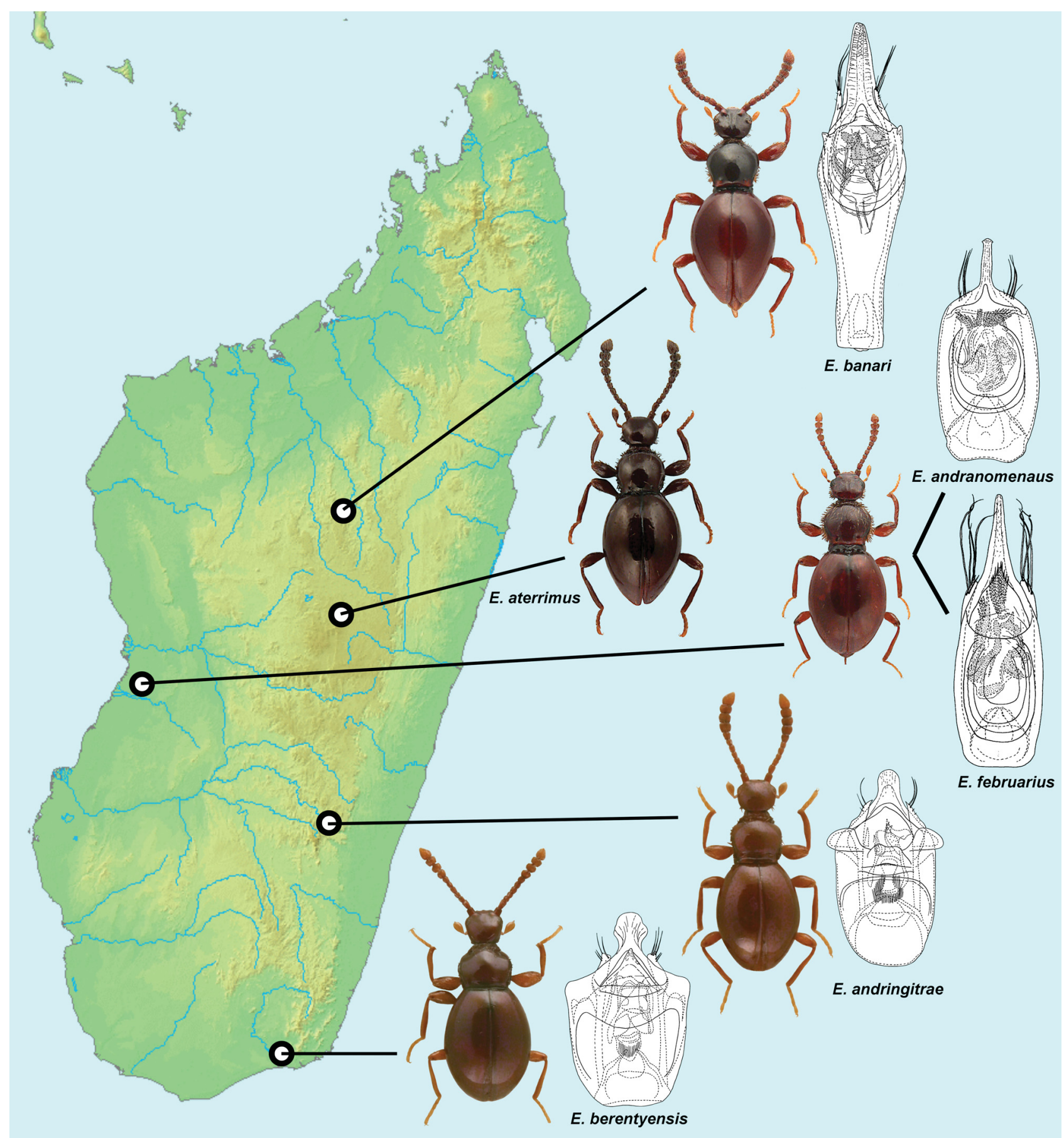

Fig. 13. Distribution of Euconnus (Glabriconnus) species in Madagascar, with dorsal habitus and aedeagus of each species (males of E. aterrimus Franz, 1986 are unknown; E. andranomenaus Jałoszyński, 2016 and E. februarius Jałoszyński, 2016 do not differ in external appearance).

1.86-1.93 mm. Euconnus andringitrae and E. berentyensis also differ from other members of Glabriconnus in having a distinct (E. andringitrae) or faint (E. berentyensis) transverse antebasal groove connecting small and weakly developed lateral antebasal pits. The presence or absence of this groove is here added to the diagnosis of Glabriconnus, to include the current knowledge of character variability.

Euconnus andringitrae and E. berentyensis share with $E$. aterrimus the evenly convex frons and vertex, and lack of a pair of diffuse longitudinal carinae, which are present in all remaining species of Glabriconnus. The two redescribed species share with E. andranomenaus two distinct hypomeral grooves well visible in lateral view, with a narrow area between them densely covered with short bristles. The small bodies, presence of an antebasal groove, and absence of a pair of frontal carinae distinguish $E$. andringitrae and $E$. berentyensis from $E$. andranomenaus. Males of $E$. andringitrae differ from those of $E$. berentyensis in different shapes of the head and pronotum (Figs 1-2), proportionally longer antennae (AnL/BL 0.52 in the former vs. 0.45 in the latter), and a clearly different aedeagus, including a different shape of the median lobe, its apical projection, the endophallic structures, and the parameres (Figs 5-8 vs. 9-12). 


\section{Acknowledgments}

I thank Harald Schillhammer (NHMW) for issuing the loan of the type specimens used in the present study.

\section{References}

FRANZ H. 1963: Scydmaeniden (Coleoptera) aus Ostafrika, dem Kongo und der Tschadrepublik (vorwiegend aus den im Sommer 1962 vom Verfasser selbst gesammelten Ausbeuten). Stuttgarter Beiträge zur Naturkunde 120: 1-93.

FRANZ H. 1986: Monographie der Scydmaeniden (Coleoptera) von Madagaskar (mit Ausschluss der Cephenniini). Österreichische Akademie der Wissenschaften, Mathematisch-Naturwissenschaftliche Klasse 125: 1-393.
HADLEY A. 2010: Combine ZP software, new version. [WWW document]. URL http://www.hadleyweb.pwp.blueyonder.co.uk/CZP/ News.htm

JAŁOSZYŃSKI P. 2016: Taxonomy of 'Euconnus complex'. Part VII. Glabriconnus, a new subgenus of Euconnus from Madagascar (Coleoptera, Staphylinidae, Scydmaeninae). Zootaxa 4084(4): 572-586. MOTSCHULSKY V. 1870: Énumération des nouvelles espèces de Coléoptères rapportés de ses voyages. 7-ième Article. Bulletin de la Société Impériale des Naturalistes de Moscou 42: 252-272.

THOMSON C. G. 1859: Skandinaviens Coleoptera, synoptiskt bearbetade. Vol. 1. Berlingska Boktryckeriet, Lund, 290 pp. 